\title{
Improved Solutions for the Optimal Coordination of DOCRs Using Firefly Algorithm
}

\author{
Muhammad Sulaiman (iD, Waseem, Shakoor Muhammad, and Asfandyar Khan (iD \\ Department of Mathematics, Abdul Wali Khan University Mardan, Mardan, Pakistan \\ Correspondence should be addressed to Muhammad Sulaiman; sulaiman513@yahoo.co.uk
}

Received 9 October 2017; Revised 24 December 2017; Accepted 11 January 2018; Published 11 February 2018

Academic Editor: Arturo Buscarino

Copyright (C) 2018 Muhammad Sulaiman et al. This is an open access article distributed under the Creative Commons Attribution License, which permits unrestricted use, distribution, and reproduction in any medium, provided the original work is properly cited.

\begin{abstract}
Nature-inspired optimization techniques are useful tools in electrical engineering problems to minimize or maximize an objective function. In this paper, we use the firefly algorithm to improve the optimal solution for the problem of directional overcurrent relays (DOCRs). It is a complex and highly nonlinear constrained optimization problem. In this problem, we have two types of design variables, which are variables for plug settings (PSs) and the time dial settings (TDSs) for each relay in the circuit. The objective function is to minimize the total operating time of all the basic relays to avoid unnecessary delays. We have considered four models in this paper which are IEEE (3-bus, 4-bus, 6-bus, and 8-bus) models. From the numerical results, it is obvious that the firefly algorithm with certain parameter settings performs better than the other state-of-the-art algorithms.
\end{abstract}

\section{Introduction}

Power systems in electrical engineering function at contrary voltage levels ranging from $415 \mathrm{~V}$ to $400 \mathrm{KV}$ or even more. Power systems consist of three parts: production, supply, and usage of the power generated. Moreover, supply lines, which transmit the power, are not insulated. These lines undergo irregularities more often than other domains of the system due to several causes like production of overcurrent due to lightening. These irregularities disrupt the provision of power and often result in the impairment of the other equipment attached to the power system. Thus, it is necessary to take protective measures in case this happens. To overcome this difficulty, overcurrent relays (OCRs) are commonly used as a safety strategy in the power system to avoid disruption in power supply and other technical faults. Hence, directional OCRs are easy to use and are an economic option for the safety of the attached subtransmission power systems and secondary layer of backup protection in transmission systems [1].

During the design of a power system, the coordination of these DOCRs is an important aspect to keep in mind. DOCRs are logical elements and are placed at both ends of a line, which helps the breaker in case any fault arises. Moreover,
DOCRs are supplied in electrical power systems to disable the faulted portions of the power systems. The problem of DOCRs is to decide which portions of the system are to function during a fault so that the faulty part is detached and does not stop the whole system, with certain constraints like adequate coordination tolerance and without extra disruptions. This procedure is mainly based on the networking of the system, nature of relays, and other protection measures as in [2]. We have two types of design variables: variables for plug settings (PSs) and the time dial settings (TDSs) for each relay in the circuit. After optimizing the design settings, the faulty lines are isolated, thus ensuring continuous supply of power to the remaining parts of the system.

In this article, the problem of DOCRs in a power system is handled with the firefly algorithm (FA) using the standard benchmark IEEE (3-, 4-, 6-, and 8-bus, resp.) systems [1, 35], as presented in Figures 8, 9, 10, and 11. The two types of decision variables are named PS and TDS. The objective of this problem is to minimize the total operating time taken by primary relays. Primary relays are expected to isolate the faulty lines satisfying the constraints on design variables.

The rest of the paper is organized as follows. In Section 2, we briefly recall different algorithms used in the literature to solve the problem of DOCRs. In Section 3, we elaborate 
the mathematical formulation of the problem. The firefly algorithm (FA) is recalled in Section 4. Parameter settings and statistical and graphical results are discussed in Section 5. Section 6 concludes the present study.

\section{Literature Review}

Initially, a trial-and-error approach was used by researchers, which consumed a large number of iterations to reach an optimal relay setting. Thus, many scientists and researchers adopted the setting of DOCRs, depending on experience. In particular, although [1] uses linear programming, however, it also uses a change of variables to convert the nonlinear problem to a linear problem, without any approximation. The problem is solved linearly in terms of the TDS and PS variables, and then after the linear solution is reached, the roots of these nonlinear expressions (TDS and PS) must be found to reach the solution for TDS and PS. In [1], the application of optimization techniques was first reported for this problem. A literature review on this problem can be found in [2]. Previously, the problem of DOCRs was handled with different techniques, like curve fitting, graph theoretical approach, and classical optimization techniques. Furthermore, a version of sparse dual revised simplex algorithm was used to solve the problem assuming nonlinear PS settings to optimize the remaining variables as for TDS settings [6]. Other techniques in linear programming, to solve the problem of DOCRs, used by [7-10] have optimized the TDS and PS settings using the simplex algorithm and the Rosenbrock hill-climbing algorithm to solve the problem.

Nature-inspired algorithms (NIAs) and artificial intelligence (AI) based techniques have been gaining the attention of researchers recently $[12,13]$. The NIAs which have been used to tackle the problem of DOCRs include, but are not limited to, particle swarm optimization (PSO) [14, 15], genetic algorithm (GA) [4, 16], modified evolutionary programming, and evolutionary programming. Expert systems [17-20] and fuzzy logic [21] are applications of AI algorithms to tackle the problem of DOCRs. A random search algorithm (RST-2) was applied to tackle the problem of DOCRs using IEEE 6-, 4-, and 3-bus models, respectively [2].

Firefly algorithm (FA) is a well-known and reliable nature-inspired algorithm for solving complex and highly nonlinear constrained optimization problems, and as far as the authors know FA is not implemented for optimization of DOCR settings using IEEE 3-, 4-, 6-, and 8-bus systems which are presented in this paper. We have implemented FA to solve the problem of DOCR settings and the outcomes of our simulations are compared with other state-of-the-art algorithms.

\section{Problem Formulation}

Determining the direction of flow of current in an electrical circuit is the job of a protection system placed in a circuit. In case a fault arises, the protection system passes the signals to the associated switch. DOCRs are useful tools to handle the situation when there are fault currents flowing in both directions. These relays operate when current flow is detected in the opposite direction. Loop systems and parallel feeders include DOCRs, because these feeders have current flowing from both ends.

There are two units of a DOCR; the first unit, which is known as the instantaneous current settings, is activated when the current is above a defined threshold. On the other hand, when the current is below a defined limit, time-delay unit is operated. This unit is activated when a fault happens with a time delay. These are two types of settings associated with the delay unit, which are named as follows:

(i) Time dialing settings (TDSs)

(ii) Plug settings (PSs) (e.g., tap setting)

The TDS points out the delayed relay, whenever the value of fault current either reaches or exceeds the picking current value. PS represents a value of the picking current for a relay [2].

3.1. Problem Formulation and Explanation. The mathematical formulation of the problem is the same as given in [4]. We have tackled the problem with the firefly algorithm. The relay working time is a nonlinear relation of the dependent variables TDS and PS and the fault current denoted by $I$ observed by the corresponding relay. So, the equation for the relay operating time is given by

$$
T=\frac{\alpha(\mathrm{TDS})}{(1 /(\mathrm{PS})(\mathrm{CT}))^{\beta}-\gamma},
$$

and the variables TDS and PS are to be determined. $\alpha, \beta$, and $\gamma$ take the values $0.14,0.02$, and 1.0 , respectively, as per [IEEE Std. (1997)]. These constants define the behavior of DOCR in terms of operating time. The value of CT keeps a level of current which is suitable for a relay. And $\mathrm{CT}^{\text {pri }}$ defines the number of windings in a current transformer (CT). Each relay is attached to a "CT," which makes $\mathrm{CT}^{\text {pri }}$ a known value. The fault current represented by $I$ is continuously measured by instruments. The line in the system is directly proportional to the number of constraints. Details of lines involved in different systems are furnished in Table 6. It is worth noting that, in real power systems, several types of relays operate besides DOCRs. The involvement of other types of relays along with DOCRs further complicates the problem by imposing more constraints as shown in Table 6.

\subsection{The Objective and Limitations of the Problem. DOCRs} need to be coordinated optimally, where optimization techniques, like firefly algorithm, minimize the corresponding objective function according to boundary and coordination limitations. The primary relay is used to clear the fault. The close-in fault is a fault which is close to the relay while a fault occurring at a far end is called a far-bus fault. By convention, the objective function is the summation of the operation time of all initial relays which clears any close-in and far-bus faults. The objective function is given by

$$
\text { objftn }=\sum_{i=1}^{N^{\mathrm{cl}}} T_{\text {pri-cl-fault }}^{i}+\sum_{j=1}^{N^{\text {far }}} T_{\text {pri-far-fault }}^{j} .
$$


In (2), $N^{\text {cl }}$ represent close-in fault relays, while $N^{\text {far }}$ denotes the number of far-bus fault relays. Also, $T_{\text {pri-cl-in }}$ shows the working time of the primary close-in fault for the relay. $T_{\text {pri-far-bus }}$ is the working time of the primary far-bus fault for the relay.

The following are the constraints.

(1) Limits on Decision Variables TDSs.

$$
\mathrm{TDS}_{i}^{\min } \leq \mathrm{TDS}^{i} \leq \mathrm{TDS}_{i}^{\max },
$$

where $i$ varies from 1 to $N^{\mathrm{cl}}$. The lowest value for $\operatorname{TDS}^{i}$ is $\operatorname{TDS}_{i}^{\min }$ which is 0.05 and the highest value is $\operatorname{TDS}_{i}^{\max }$ which is 1.1.

(2) Limits on Decision Variables PSs.

$$
\mathrm{PS}_{i}^{\min } \leq \mathrm{PS}^{i} \leq \mathrm{PS}_{i}^{\max },
$$

where $i$ varies from 1 to $N^{\mathrm{cl}}$. $\mathrm{PS}_{i}^{\mathrm{min}}$ is the lowest value which is 1.25 and $\mathrm{PS}_{i}^{\max }$ is the highest value of $\mathrm{PS}^{i}$ which is 1.50 .

(3) Bounds on Initial Working Times. According to this constraint, each term of the objective is bounded in the interval $[0.05,1]$.

(4) Constraints on the Selection of Pairs of the Relays.

$$
T^{\text {backup }}-T^{\text {primary }}-\text { CTI } \geq 0,
$$

where $T^{\text {backup }}$ is the working time of backup relay, $T^{\text {primary }}$ is the working time of primary relay, and CTI is the coordinating time interval.

3.3. The IEEE 3-Bus System. In this problem, the values of $N^{\mathrm{cl}}$ and $N^{\mathrm{far}}$ are taken as 6 which is twice the number of lines involved. There are 12 decision variables, namely, $\mathrm{TDS}_{1}$ to $\mathrm{TDS}_{6}$ and $\mathrm{PS}_{1}$ to $\mathrm{PS}_{6}$. Figure 8 represents the model for the 3 -bus system. The objective (objftn) to be minimized is given in

$$
\text { objftn }=\sum_{i=1}^{6} T_{\text {pri-cl-fault }}^{i}+\sum_{j=1}^{6} T_{\text {pri-far-fault }}^{j}
$$

where

$$
\begin{aligned}
T_{\text {pri-cl-fault }}^{i} & =\frac{0.14 \times \mathrm{TDS}_{i}}{\left(a^{i} /\left(\mathrm{PS}^{i} \times b^{i}\right)\right)^{0.02}-1}, \\
T_{\text {pri-far-fault }}^{i} & =\frac{0.14 \times \mathrm{TDS}_{j}}{\left(c^{j} /\left(\mathrm{PS}^{j} \times d^{j}\right)\right)^{0.02}-1} .
\end{aligned}
$$

The rest of the constants $a^{i}, b^{i}, c^{i}$, and $d^{i}$ are given in Table 7; see the Appendix.

Descriptions of different constraints for the model are given below.

Limits on Variables TDSs. $\mathrm{TDS}_{i}^{\min } \leq \mathrm{TDS}^{i} \leq \mathrm{TDS}_{i}^{\max }$, where $i$ starts from 1 and varies to $6\left(N^{\mathrm{cl}}\right)$.

Limits on Variables PSs. $\mathrm{PS}_{i}^{\min } \leq \mathrm{PS}^{i} \leq \mathrm{PS}_{i}^{\max }$, where $i$ starts from 1 and varies to $6\left(N^{\mathrm{cl}}\right)$.
Bounds on Initial Working Time. According to this constraint, each term of the objective is bounded in the interval $[0.05,1]$.

Constraints on the Selection of Pairs of the Relays.

$$
T^{\text {backup }}-T^{\text {primary }}-\mathrm{CTI} \geq 0,
$$

where $T^{\text {backup }}$ is the working time of the backup relay and $T^{\text {primary }}$ is the working time of the primary relay. The value of CTI is 0.3 . Here,

$$
\begin{aligned}
T_{\text {backup }} & =\frac{0.14\left(\mathrm{TDS}^{p}\right)}{\left(e^{i} /\left(\mathrm{PS}^{p}\right)\left(f^{i}\right)\right)^{0.02}-1}, \\
T_{\text {primary }} & =\frac{0.14\left(\mathrm{TDS}^{q}\right)}{\left(g^{i} /\left(\mathrm{PS}^{q}\right)\left(h^{i}\right)\right)^{0.02}-1} .
\end{aligned}
$$

Table 8 represents the values of constants $p, q, e^{i}, f^{i}, g^{i}$, and $h^{i}$.

3.4. The IEEE 4-Bus System. In this problem, the values of $N^{\mathrm{cl}}$ and $N^{\mathrm{far}}$ are taken as 8 which is twice the number of lines involved. There are 16 decision variables, namely, TDS $_{1}$ to $\mathrm{TDS}_{8}$ and $\mathrm{PS}_{1}$ to $\mathrm{PS}_{8}$. Figure 9 represents the model for the 4-bus system. The value of CTI for this system is 0.3. There are 9 selectivity constraints. The mathematical form for this model will be as in (6) with $N^{\mathrm{cl}}=8$. The rest of the constants $a^{i}, b^{i}, c^{i}$, and $d^{i}$ and $e^{i}, f^{i}, g^{i}, h^{i}$ for the 4 -bus system are given in Tables 9 and 10; see the Appendix.

3.5. The IEEE 6-Bus System. This problem of coordination of DOCRs is named the IEEE 6-bus system; both $N^{\mathrm{cl}}$ and $N^{\text {far }}$ take a value equal to 14 . Basically, this problem is comprised of 28 design variables (two for each relay), that is, $\mathrm{TDS}_{1}$ to $\mathrm{TDS}_{14}$ and $\mathrm{PS}_{1}$ to $\mathrm{PS}_{14}$. Figure 10 represents the model for the 6-bus system. CTI takes the value 0.2 . For the current sample of the 6-bus system, there are 38 selectivity constraints for all faults detected by the corresponding relay. Considering the observations given in [2], 10 constraints are relaxed. The mathematical form for this model will be as in (6). The rest of the constants $a^{i}, b^{i}, c^{i}$, and $d^{i}$ and $e^{i}, f^{i}, g^{i}, h^{i}$ for the 6-bus system are given in Tables 11 and 12; see the Appendix.

3.6. The IEEE 8-Bus System. The last model investigated in this study is the 8-bus system as shown in Figure 11. The mathematical form of this model will be as in (6). It consists of 8 buses, 14 relays, 7 lines, 2 transformers, and 2 generators. The main characteristics of this system are given in Tables 13 and 14 . Therefore, this 8 -bus system has 28 design variables and 40 constraints [3].

\section{Firefly Algorithm}

The firefly algorithm was introduced by Yang in [11], and it simulates the flashing phenomena of fireflies. To simulate the idea, the following assumptions are made $[9,11]$.

All fireflies are of the same gender. Brighter fireflies have greater attraction than others with less brightness. The 
attraction will decrease with the increase in distance between fireflies. If none of the fireflies is brighter than a specific one, then it will move randomly.

The landscape of the given objective function affects the brightness of a firefly [11]. For a maximization problem, the relation of brightness $I$ and the objective function can be represented as $I(x) \alpha f(x)$. The second assumption can be represented mathematically as in (10) and (11).

$$
I(r)=\left(I_{0}\right)\left(e^{-\gamma r^{2}}\right)
$$

where $I_{0}$ is the actual intensity of light and $\gamma$ is called the light absorption coefficient. The attractiveness $\beta$ can be related as follows:

$$
\beta(r)=\left(\beta_{0}\right)\left(e^{-\gamma r^{2}}\right)
$$

where $r$ represents the distance between two fireflies and $\beta_{0}$ is their actual attractiveness at $r=0$. The distance $r_{i j}$ between two fireflies at positions $x_{i}$ and $x_{j}$ can be calculated as follows:

$$
r_{i j}=\left\|x_{i}-x_{j}\right\|=\sqrt{\sum_{k=1}^{d}\left(x_{i, k}-x_{j, k}\right)},
$$

where $x_{i, k}$ is the $k$ th component of the spatial coordinate $x_{i}$ of the $i$ th firefly. The movement of a firefly $i$ which is attracted to another more attractive (brighter) firefly $j$ is determined by

$$
x_{i}=x_{i}+\alpha\left(\operatorname{rand}-\frac{1}{2}\right)+\beta_{0} e^{-\gamma r_{i j}^{2}}\left(x_{j}-x_{i}\right) .
$$

Here, $\alpha$ is a random parameter in the interval $[0,1]$. And rand is a random number drawn from a uniform Gaussian distribution in $[0,1]$. A pseudocode for the firefly algorithm is given in Algorithm 1.

\section{Simulation Settings and Discussion on Results}

For a fair comparison, the population size is fixed. We have executed FA a fixed number of times to get better values for the decision variables. Based on the analysis given in [2], the size of the population is fixed as 50 , the constant CR is taken as 0.5 , and the scaling factor $(\mathrm{F})$ is set as 0.5 for differential evolution. The stopping criterion is either that the algorithm completes 1000 generations or that we get an optimal value which satisfies the following condition: $\left|f_{\max }-f_{\min }\right| \leq 10^{-4}$. Here, $f$ is the objective value. Constraints are handled using the penalty function approach. All experiments are repeated 30 times and a global optimum solution is recorded for each algorithm.

The best solutions obtained by FA and other versions of DE for the IEEE 3-bus model in terms of best decision features, minimum objective function value, and number of function evaluations taken to complete each simulation are given in Table 1 and Figures 1 and 2 . Here, it is evident that, in terms of the objective function value, DE gave the worse objective value (4.8422) and all the other versions of the DE

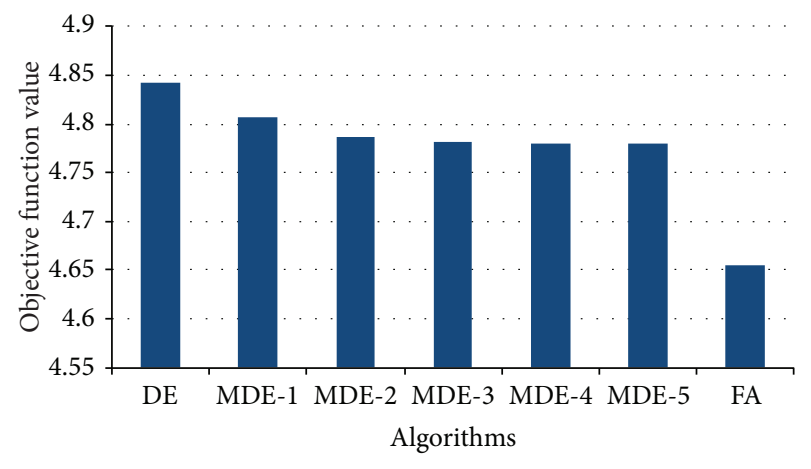

FIGURE 1: Best results obtained, for the IEEE 3-bus model, by different techniques are compared with the firefly algorithm.

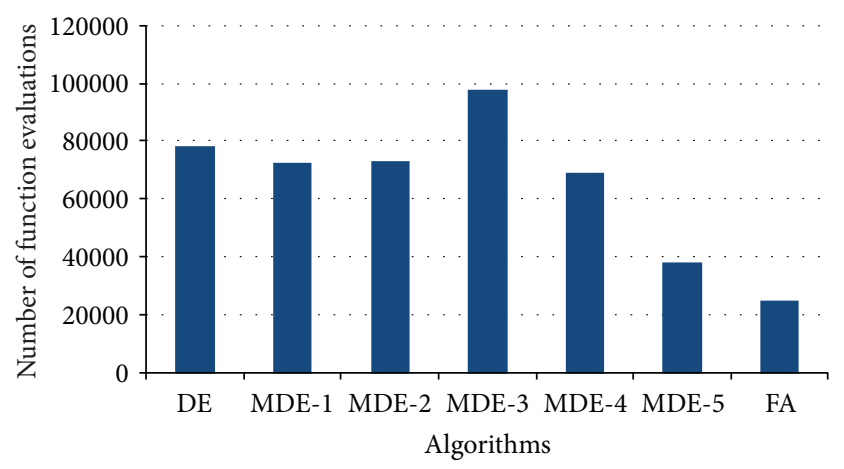

Figure 2: The number of function evaluations done by different algorithms to solve the 3-bus model.

algorithm gave almost similar values. On the other hand, FA gave us an objective value of 4.6557 , which is much better than other algorithms. However, if we compare the number of function evaluations (NFE), then the performance of DE and its variants is worse as compared to the FA algorithm as it took only $25200 \mathrm{NFE}$ to complete the simulations. Thus, FA is significantly better than all the other algorithms under consideration.

The simulation results of the IEEE 4-bus model are given in Table 2 and Figures 3 and 4. It is observed for the IEEE 4-bus model that DE algorithm and all the variants of the DE algorithm performed in a similar manner in terms of objective function values with MDE-4 giving a slightly better value than other variant algorithms of DE. But FA outperformed the algorithms under consideration in terms of the number of function evaluations (NFE). Better performance was shown by FA, which took 35500 NFE to converge to a solution 3.5624 .

Furthermore, the results for the IEEE 6-bus model as in Table 3 and Figures 5 and 6 , in terms of the best objective function value, are again slightly different from each other with MDE-4 and MDE-5 giving slightly improved solutions than other variant algorithms of DE. On the other hand, FA gave us an objective value of 10.3232, which is much better than other results in the table. However, in terms of NFE, 


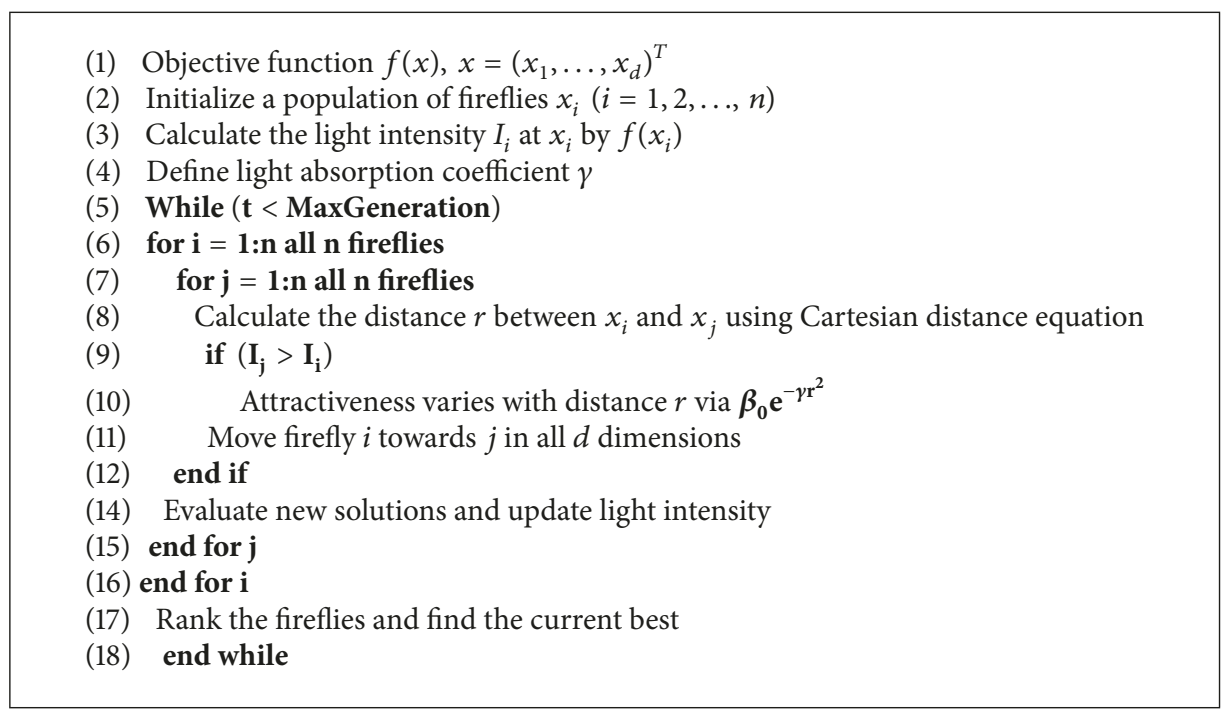

Algorithm 1: Pseudocode for firefly algorithm [11].

TABLE 1: Best design variables, objective function values (F), and total number of function evaluations (NFE) for IEEE 3-bus model by DE, modified DE, and firefly algorithms.

\begin{tabular}{lccccccc}
\hline & DE & MDE-1 & MDE-2 & MDE-3 & MDE-4 & MDE-5 \\
\hline $\mathrm{TS}_{1}$ & 0.0500 & 0.0500 & 0.0500 & 0.0500 & 0.0500 & 0.0500 & 0.0500 \\
$\mathrm{TS}_{2}$ & 0.2194 & 0.2178 & 0.1979 & 0.1988 & 0.1976 & 0.1976 \\
$\mathrm{TS}_{3}$ & 0.0500 & 0.0500 & 0.0500 & 0.0500 & 0.0500 & 0.0500 \\
$\mathrm{TS}_{4}$ & 0.2135 & 0.2090 & 0.2094 & 0.2090 & 0.2090 & 0.2090 & 0.0500 \\
$\mathrm{TS}_{5}$ & 0.19498 & 0.1812 & 0.1847 & 0.1812 & 0.1812 & 0.1812 \\
$\mathrm{TS}_{6}$ & 0.1953 & 0.1807 & 0.1827 & 0.1807 & 0.1806 & 0.1806 \\
$\mathrm{PS}_{1}$ & 1.250 & 1.250 & 1.250 & 1.250 & 1.250 & 1.250 \\
$\mathrm{PS}_{2}$ & 1.250 & 1.250 & 1.4999 & 1.4849 & 1.4999 & 0.1290 \\
$\mathrm{PS}_{3}$ & 1.2500 & 1.250 & 1.250 & 1.250 & 1.250 & 1.500 \\
$\mathrm{PS}_{4}$ & 1.4605 & 1.4999 & 1.4999 & 1.4999 & 1.4999 & 1.250 \\
$\mathrm{PS}_{5}$ & 1.250 & 1.500 & 1.4318 & 1.4998 & 1.4999 & 1.500 \\
$\mathrm{PS}_{6}$ & 1.250 & 1.4999 & 1.4619 & 1.4999 & 1.4999 & 1.500 \\
$\mathrm{~F}$ & 4.8422 & 4.80707 & 4.7873 & 4.7822 & 4.7806 & 1.500 \\
$\mathrm{NFE}$ & 78360 & 72350 & 73350 & 97550 & 69270 & 1.3950 \\
& & & & & 1.2500 \\
\end{tabular}

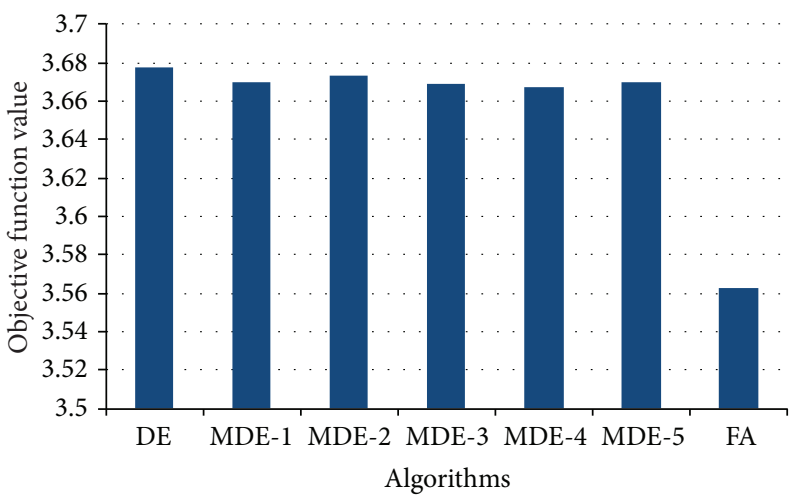

FIGURE 3: Best results obtained, for the IEEE 4-bus model, by different techniques are compared with the firefly algorithm. 


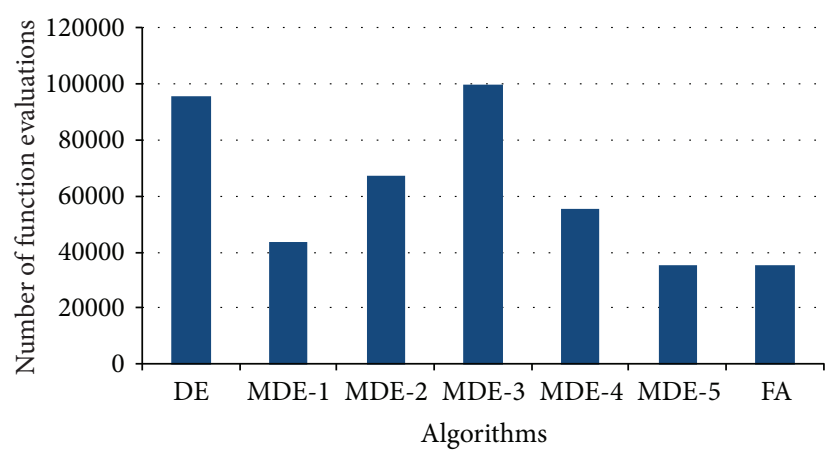

FIgURE 4: The number of function evaluations done by different algorithms to solve the 4-bus model.

TABLE 2: Best design variables, objective function values (F), and number of function evaluations (NFE) for IEEE 4-bus model by DE, modified $\mathrm{DE}$, and firefly algorithms.

\begin{tabular}{lccccccc}
\hline & DE & MDE-1 & MDE-2 & MDE-3 & MDE-4 & MDE-5 \\
\hline $\mathrm{TS}_{1}$ & 0.0500 & 0.0500 & 0.0500 & 0.0500 & 0.0500 & 0.0500 & 0.0500 \\
$\mathrm{TS}_{2}$ & 0.2248 & 0.2121 & 0.2123 & 0.2121 & 0.2121 & 0.2121 & 0.0920 \\
$\mathrm{TS}_{3}$ & 0.0500 & 0.0500 & 0.0500 & 0.0500 & 0.0500 & 0.0500 \\
$\mathrm{TS}_{4}$ & 0.1515 & 0.1515 & 0.1515 & 0.1515 & 0.1515 & 0.1515 & 0.0500 \\
$\mathrm{TS}_{5}$ & 0.1264 & 0.1264 & 0.1264 & 0.1264 & 0.1262 & 0.1264 \\
$\mathrm{TS}_{6}$ & 0.0500 & 0.0500 & 0.0500 & 0.0500 & 0.0500 & 0.0500 \\
$\mathrm{TS}_{7}$ & 0.1337 & 0.1338 & 0.1371 & 0.1338 & 0.1337 & 0.1337 \\
$\mathrm{TS}_{8}$ & 0.0500 & 0.0500 & 0.0500 & 0.0500 & 0.0500 & 0.0500 \\
$\mathrm{PS}_{1}$ & 1.2734 & 1.2733 & 1.2733 & 1.2733 & 1.250 & 0.0500 \\
$\mathrm{PS}_{2}$ & 1.250 & 1.4998 & 1.4959 & 1.500 & 1.500 & 1.2734 \\
$\mathrm{PS}_{3}$ & 1.2500 & 1.2500 & 1.2500 & 1.250 & 1.250 & 1.4999 \\
$\mathrm{PS}_{4}$ & 1.4997 & 1.4996 & 1.4997 & 1.4995 & 1.500 & 1.2500 \\
$\mathrm{PS}_{5}$ & 1.4997 & 1.500 & 1.500 & 1.4997 & 1.500 & 1.4999 \\
$\mathrm{PS}_{6}$ & 1.250 & 1.2500 & 1.250 & 1.250 & 1.250 & 1.0571 \\
$\mathrm{PS}_{7}$ & 1.500 & 1.4997 & 1.4274 & 1.4995 & 1.4998 & 1.3900 \\
$\mathrm{PS}_{8}$ & 1.250 & 1.250 & 1.250 & 1.250 & 1.250 & 1.2500 \\
$\mathrm{~F}$ & 3.6774 & 3.6694 & 3.6734 & 3.6692 & 3.6674 & 1.500 \\
$\mathrm{NFE}^{9}$ & 95400 & 43400 & 67200 & 99700 & 55100 & 1.250 \\
\end{tabular}

the worst convergence rate was shown by DE while FA took $49980 \mathrm{NFE}$ to get the best solution presented in the table.

The last problem in this study is the 8-bus model. The results for the IEEE 8 -bus model as in Table 4 and Figure 7, in terms of the best objective function values, are again in favor of FA. It is observed that, according to the quoted results obtained by the electromagnetic field optimization (EFO) algorithm, differential evolution (DE) algorithm, particle swarm optimization (PSO) algorithm, black hole $(\mathrm{BH})$ algorithm, electromagnetism-like mechanism (EM), biogeography-based optimization (BBO), and harmony search (HS) [3] are slightly different from each other with EM, HS, BH, and PSO giving the worst results, while EFO, DE, and BBO gave improved solutions. On the other hand, FA gave us an objective value of 6.6463 which is much better than other results in the table.

Moreover, results obtained by FA are compared to previously quoted results of DE and MDE versions, RST-2, GA, SOMA, SOM-GA, LX-POL, and LX-PM [2, 4, 14]. The experimental outcomes are recorded in Tables 1-5 in terms of the best objective value and total number of function evaluations. Graphical analyses are presented, for each system, in shape of bar graphs given in Figures 1-7. Concise data is recorded in Table 5 which compares FA to other state-ofthe-art algorithms. All experimental results suggest that FA can tackle all the three problems efficiently and optimally. It is noted that FA consumes a smaller number of function evaluations as compared to other methods. 


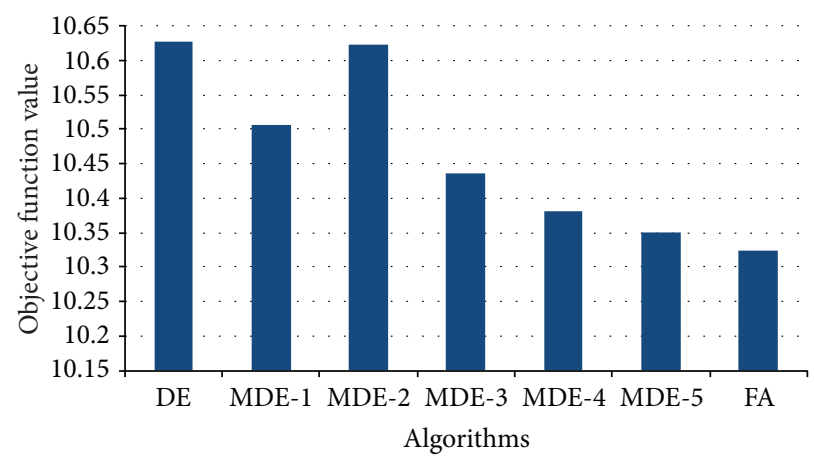

FIGURE 5: Best results obtained, for the IEEE 6-bus model, by different techniques are compared with the firefly algorithm.

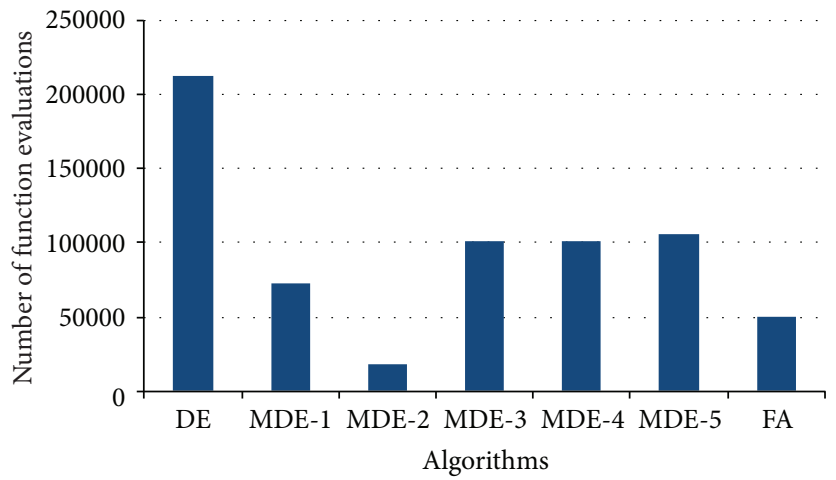

FIGURE 6: The number of function evaluations done by different algorithms to solve the 6-bus model.

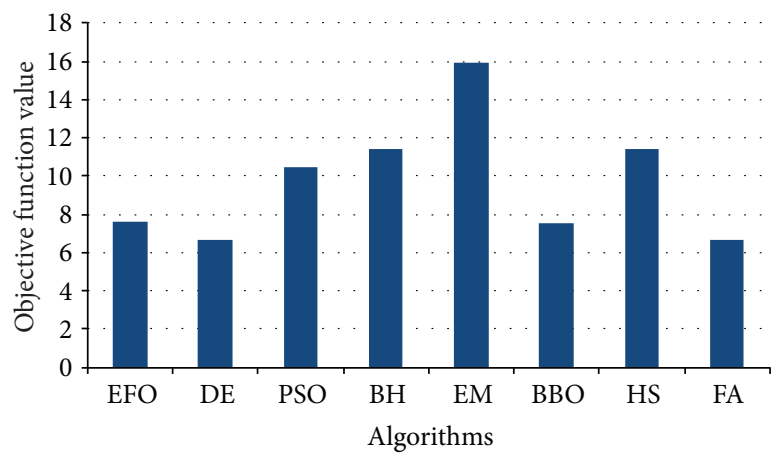

FIGURE 7: Best results obtained, for the IEEE 8-bus model, by different techniques are compared with the firefly algorithm [3].

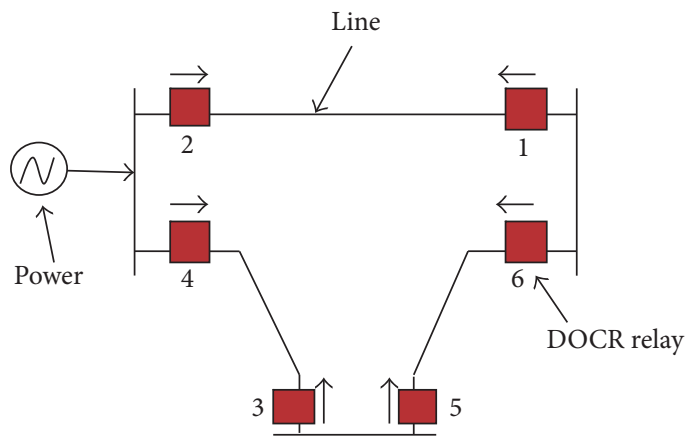

FIGURE 8: Model for the IEEE 3-bus system. 
TABLE 3: Best design variables, objective function values (F), and total number of function evaluations (NFE) for IEEE 6-bus model by DE, modified DE, and firefly algorithms.

\begin{tabular}{|c|c|c|c|c|c|c|c|}
\hline & $\mathrm{DE}$ & MDE-1 & MDE-2 & MDE-3 & MDE-4 & MDE-5 & FA \\
\hline $\mathrm{TS}_{1}$ & 0.1173 & 0.1171 & 0.1149 & 0.1034 & 0.1144 & 0.1024 & 0.7976 \\
\hline $\mathrm{TS}_{2}$ & 0.2082 & 0.1866 & 0.2037 & 0.1863 & 0.1864 & 0.1863 & 0.4522 \\
\hline $\mathrm{TS}_{3}$ & 0.0997 & 0.0965 & 0.0982 & 0.0961 & 0.0947 & 0.0946 & 0.1524 \\
\hline $\mathrm{TS}_{4}$ & 0.1125 & 0.1119 & 0.10367 & 0.1125 & 0.1006 & 0.1067 & 0.4740 \\
\hline $\mathrm{TS}_{5}$ & 0.0500 & 0.0500 & 0.0500 & 0.0500 & 0.0500 & 0.0500 & 0.5339 \\
\hline $\mathrm{TS}_{6}$ & 0.0580 & 0.0500 & 0.0500 & 0.0500 & 0.0500 & 0.0500 & 0.2565 \\
\hline $\mathrm{TS}_{7}$ & 0.0500 & 0.0500 & 0.0500 & 0.0500 & 0.0500 & 0.0500 & 0.08948 \\
\hline $\mathrm{TS}_{8}$ & 0.0500 & 0.0500 & 0.0500 & 0.0500 & 0.0500 & 0.0500 & 0.3796 \\
\hline $\mathrm{TS}_{9}$ & 0.0500 & 0.0500 & 0.0500 & 0.0500 & 0.0500 & 0.0500 & 0.3313 \\
\hline $\mathrm{TS}_{10}$ & 0.0719 & 0.0706 & 0.0575 & 0.0703 & 0.0701 & 0.0563 & 0.0980 \\
\hline $\mathrm{TS}_{11}$ & 0.0649 & 0.0649 & 0.0667 & 0.0649 & 0.0649 & 0.0650 & 0.3816 \\
\hline $\mathrm{TS}_{12}$ & 0.0617 & 0.0617 & 0.0566 & 0.0509 & 0.0509 & 0.0553 & 0.5236 \\
\hline $\mathrm{TS}_{13}$ & 0.0500 & 0.0500 & 0.0635 & 0.0500 & 0.0500 & 0.0500 & 0.8287 \\
\hline $\mathrm{TS}_{14}$ & 0.0856 & 0.0860 & 0.0859 & 0.0857 & 0.0709 & 0.0709 & 0.3320 \\
\hline $\mathrm{PS}_{1}$ & 1.2505 & 1.2515 & 1.2635 & 1.4995 & 1.2602 & 1.4991 & 1.3909 \\
\hline $\mathrm{PS}_{2}$ & 1.2500 & 1.4959 & 1.2993 & 1.4999 & 1.4987 & 1.4999 & 1.3483 \\
\hline $\mathrm{PS}_{3}$ & 1.2512 & 1.2525 & 1.2622 & 1.2575 & 1.2761 & 1.2771 & 1.2674 \\
\hline $\mathrm{PS}_{4}$ & 1.2515 & 1.2632 & 1.4322 & 1.2508 & 1.4992 & 1.3650 & 1.4622 \\
\hline $\mathrm{PS}_{5}$ & 1.2500 & 1.2500 & 1.2500 & 1.2500 & 1.2500 & 1.2500 & 1.3329 \\
\hline $\mathrm{PS}_{6}$ & 1.2500 & 1.3822 & 1.3885 & 1.3810 & 1.3814 & 1.3818 & 1.3563 \\
\hline $\mathrm{PS}_{7}$ & 1.2500 & 1.2500 & 1.2508 & 1.2500 & 1.2500 & 1.2500 & 1.4024 \\
\hline $\mathrm{PS}_{8}$ & 1.2500 & 1.2501 & 1.2500 & 1.2500 & 1.2505 & 1.2500 & 1.317 \\
\hline $\mathrm{PS}_{9}$ & 1.2502 & 1.2500 & 1.2514 & 1.2500 & 1.2500 & 1.2500 & 1.3291 \\
\hline $\mathrm{PS}_{10}$ & 1.2502 & 1.2501 & 1.4970 & 1.2521 & 1.2500 & 1.4996 & 1.3830 \\
\hline $\mathrm{PS}_{11}$ & 1.4998 & 1.4999 & 1.4759 & 1.4998 & 1.4999 & 1.4998 & 1.2923 \\
\hline $\mathrm{PS}_{12}$ & 1.2575 & 1.2529 & 1.4700 & 1.4997 & 1.5000 & 1.3931 & 1.3817 \\
\hline $\mathrm{PS}_{13}$ & 1.4805 & 1.4664 & 1.2728 & 1.4647 & 1.4615 & 1.4613 & 1.4035 \\
\hline $\mathrm{PS}_{14}$ & 1.2557 & 1.2500 & 1.2624 & 1.2540 & 1.4979 & 1.4974 & 1.2921 \\
\hline $\mathrm{F}$ & 10.6272 & 10.5067 & 10.6238 & 10.4370 & 10.3812 & 10.3514 & 10.3232 \\
\hline NFE & 212190 & 72960 & 18180 & 101580 & 100860 & 106200 & 49980 \\
\hline
\end{tabular}

\section{Conclusion}

In electrical engineering, the problem of optimal coordination of several directional overcurrent relays is NP-hard with many constraints. The mathematical nature of the problem is highly complex, with several constraints imposed on the objective function. The problem of DOCRs requires suitable and robust optimization algorithms to tackle it. Experimental results obtained by FA are compared to previously quoted results of DE, RST-2, GA, SOMA, SOM-GA, LXPOL, LXPM, $\mathrm{EFO}, \mathrm{PSO}, \mathrm{BH}, \mathrm{EM}, \mathrm{BBO}$, and HS. In order to summarize the achievements of the research, we present the following key aspects:

(i) In this paper, we implemented the firefly algorithm (FA) to improve the solutions for four optimization problems, namely, the IEEE (3-, 4-, 6-, and 8-bus) systems.

(ii) To tackle the DOCR problems, the use of a suitable and efficient metaheuristic is needed. (iii) The outcome of our simulations shows that FA can efficiently minimize all the four models of the problem.

(iv) The efficiency of FA can be observed from the minimum function evaluations required by the algorithm to reach the optimum as compared to other state-ofthe-art algorithms.

(v) The outcome suggests that FA is overall better and more efficient than the other optimization techniques considered in this research.

(vi) In the future, one can extend this work to solve problems of higher buses and complex power systems. Moreover, extensive statistical analysis and parameters tuning can further highlight and improve the efficiency of FA.

\section{Appendix}

Tables 6-14 for IEEE 3-, 4-, 6-, and 8-bus systems. 


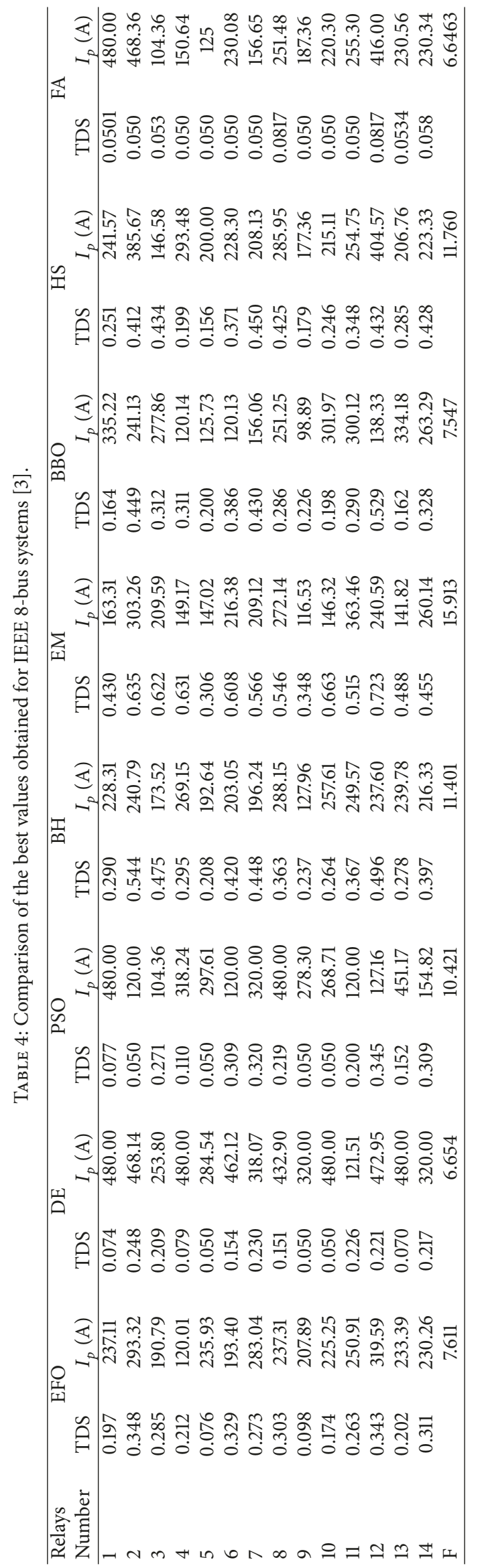


TABLE 5: Comparison of the best values obtained for IEEE (3-, 4-, and 6-bus) systems.

\begin{tabular}{lccc}
\hline Algorithms & 3-bus model & 4-bus model & 6-bus model \\
\hline FA & 4.6557 & 3.5624 & 10.3232 \\
DE & 4.8421 & 3.6774 & 10.6272 \\
MDE-1 & 4.8069 & 3.6694 & 10.5067 \\
MDE-2 & 4.7872 & 3.6734 & 10.6238 \\
MDE-3 & 4.7822 & 3.6692 & 10.4370 \\
MDE-4 & 4.7806 & 3.6674 & 10.3812 \\
MDE-5 & 4.7806 & 3.6694 & 10.3514 \\
RST-2 & 4.8354 & 3.7050 & 10.6192 \\
GA & 5.0761 & 3.8587 & 13.7996 \\
SOMA & 8.0101 & 3.7892 & 26.1495 \\
SOM-GA & 4.7898 & 3.6745 & 10.3578 \\
LX-POL & 4.8265 & 3.5749 & 10.6028 \\
LX-PM & 4.8286 & 3.5830 & 10.6219 \\
\hline
\end{tabular}

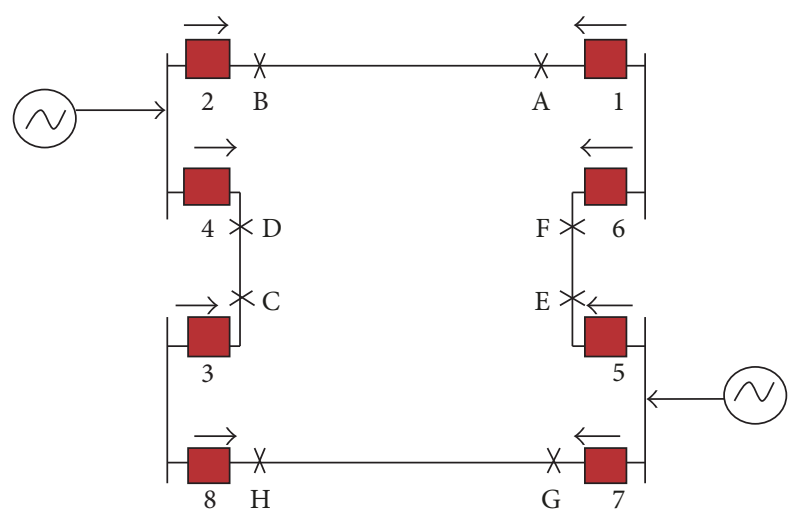

FIgure 9: Model for the IEEE 4-bus system.

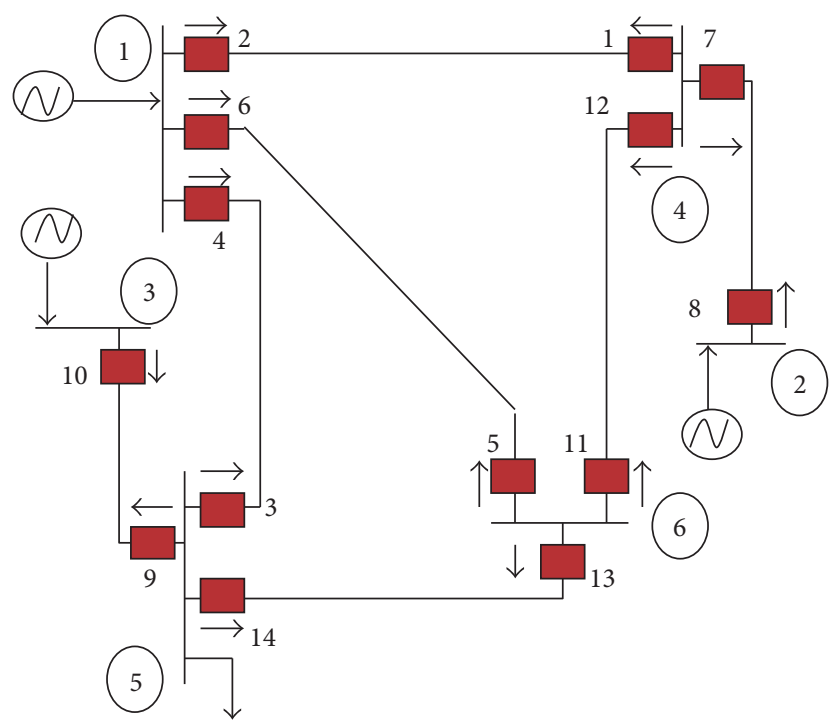

FIGURE 10: Model for the IEEE 6-bus system. 
TABLE 6: The complexity of the DOCR problems as the bus size increases.

\begin{tabular}{lcccc}
\hline Number & IEEE 3-bus & IEEE 4-bus & IEEE 6-bus & IEEE 8-bus \\
\hline Number of lines & 3 & 4 & 7 & 7 \\
Number of DOCRs (relays) & 6 & 8 & 14 & 14 \\
Number of decision variables & 12 & 16 & 28 & 28 \\
Number of selectivity constraints & 8 & 9 & 104 & 40 \\
Number of restricted constraints & 24 & 32 & 104 \\
\hline
\end{tabular}

TABLe 7: Values of constants $a^{i}, b^{i}, c^{i}$, and $d^{i}$ for Model 1.

\begin{tabular}{|c|c|c|c|c|c|}
\hline$T_{\text {pri-cl-fault }}^{i}$ & & & $T_{\text {pri-far-fault }}^{i}$ & & \\
\hline $\mathrm{TDS}^{i}$ & $a^{i}$ & $b^{i}$ & $\mathrm{TDS}^{j}$ & $c^{j}$ & $d^{j}$ \\
\hline $\mathrm{TDS}^{1}$ & 9.46 & 2.06 & TDS $^{2}$ & 100.63 & 2.06 \\
\hline $\mathrm{TDS}^{2}$ & 26.91 & 2.06 & $\mathrm{TDS}^{1}$ & 14.08 & 2.06 \\
\hline $\mathrm{TDS}^{3}$ & 8.81 & 2.23 & $\mathrm{TDS}^{4}$ & 136.23 & 2.23 \\
\hline $\mathrm{TDS}^{4}$ & 37.68 & 2.23 & $\mathrm{TDS}^{3}$ & 12.07 & 2.23 \\
\hline $\mathrm{TDS}^{5}$ & 17.93 & 0.8 & TDS $^{6}$ & 19.2 & 0.8 \\
\hline $\mathrm{TDS}^{6}$ & 14.35 & 0.8 & $\mathrm{TDS}^{5}$ & 25.9 & 0.8 \\
\hline
\end{tabular}

TABLE 8: Values of constants $e^{i}, f^{i}, g^{i}$, and $h^{i}$ for Model I.

\begin{tabular}{|c|c|c|c|c|c|}
\hline \multirow{2}{*}{$\begin{array}{l}t_{\text {backup }}^{i} \\
p \\
\end{array}$} & \multicolumn{5}{|c|}{$t_{\text {primary }}^{i}$} \\
\hline & $e^{i}$ & $f^{i}$ & $q$ & $g^{i}$ & $h^{i}$ \\
\hline 5 & 14.08 & 0.8 & 1 & 14.08 & 2.06 \\
\hline 6 & 12.07 & 0.8 & 3 & 12.07 & 2.23 \\
\hline 4 & 25.9 & 2.23 & 5 & 25.9 & 0.8 \\
\hline 2 & 14.35 & 0.8 & 6 & 14.35 & 2.06 \\
\hline 5 & 9.46 & 0.8 & 1 & 9.46 & 2.06 \\
\hline 6 & 8.81 & 0.8 & 3 & 8.81 & 2.23 \\
\hline 2 & 19.2 & 2.06 & 6 & 19.2 & 0.8 \\
\hline 4 & 17.93 & 2.23 & 5 & 17.93 & 0.8 \\
\hline
\end{tabular}

TABLE 9: Values of constants $a^{i}, b^{i}, c^{i}$, and $d^{i}$ for Model II.

\begin{tabular}{|c|c|c|c|c|c|}
\hline \multirow{2}{*}{$\begin{array}{l}T_{\text {pri-cl-fault }}^{i} \\
\text { TDS }^{i}\end{array}$} & \multicolumn{5}{|c|}{$T_{\text {pri-far-fault }}^{i}$} \\
\hline & $a^{i}$ & $b^{i}$ & TDS $^{j}$ & $c^{j}$ & $d^{j}$ \\
\hline TDS $^{1}$ & 20.32 & 0.48 & $\mathrm{TDS}^{2}$ & 23.75 & 0.48 \\
\hline $\mathrm{TDS}^{2}$ & 88.85 & 0.48 & $\mathrm{TDS}^{1}$ & 12.48 & 0.48 \\
\hline $\mathrm{TDS}^{3}$ & 13.61 & 1.1789 & $\mathrm{TDS}^{4}$ & 31.92 & 1.1789 \\
\hline $\mathrm{TDS}^{4}$ & 116.81 & 1.1789 & $\mathrm{TDS}^{3}$ & 10.38 & 1.1789 \\
\hline $\mathrm{TDS}^{5}$ & 116.7 & 1.5259 & $\mathrm{TDS}^{6}$ & 12.07 & 1.5259 \\
\hline $\mathrm{TDS}^{6}$ & 16.67 & 1.5259 & $\mathrm{TDS}^{5}$ & 31.92 & 1.5259 \\
\hline $\mathrm{TDS}^{7}$ & 71.7 & 1.2018 & $\mathrm{TDS}^{8}$ & 11 & 1.2018 \\
\hline $\mathrm{TDS}^{8}$ & 19.27 & 1.2018 & $\mathrm{TDS}^{7}$ & 18.91 & 1.2018 \\
\hline
\end{tabular}


TABLE 10: Values of constants $e^{i}, f^{i}, g^{i}$, and $h^{i}$ for Model II.

\begin{tabular}{|c|c|c|c|c|c|}
\hline$\overline{T_{\text {backup }}^{i}}$ & & & $T_{\text {prima }}^{i}$ & & \\
\hline$p$ & $e^{i}$ & $f^{i}$ & $q$ & $g^{i}$ & $h^{i}$ \\
\hline 5 & 20.32 & 1.5259 & 1 & 20.32 & 0.48 \\
\hline 5 & 12.48 & 1.5259 & 1 & 12.48 & 0.48 \\
\hline 7 & 13.61 & 1.2018 & 3 & 13.61 & 1.1789 \\
\hline 7 & 10.38 & 1.2018 & 3 & 10.38 & 1.1789 \\
\hline 1 & 1.16 & 0.48 & 4 & 116.81 & 1.1789 \\
\hline 2 & 12.07 & 0.48 & 6 & 12.07 & 1.1789 \\
\hline 2 & 16.67 & 0.48 & 6 & 16.67 & 1.5259 \\
\hline 4 & 11 & 1.1789 & 8 & 11 & 1.2018 \\
\hline 4 & 19.27 & 1.1789 & 8 & 19.27 & 1.2018 \\
\hline
\end{tabular}

TABLE 11: Values of constants $a^{i}, b^{i}, c^{i}$, and $d^{i}$ for Model III.

\begin{tabular}{|c|c|c|c|c|c|}
\hline \multirow{2}{*}{$\begin{array}{l}T_{\text {pri-cl-fault }}^{i} \\
\text { TDS }^{i}\end{array}$} & \multicolumn{5}{|c|}{$T_{\text {pri-far-fault }}^{i}$} \\
\hline & $a^{i}$ & $b^{i}$ & $\mathrm{TDS}^{j}$ & $c^{j}$ & $d^{j}$ \\
\hline $\mathrm{TDS}^{1}$ & 2.5311 & 0.2585 & $\mathrm{TDS}^{2}$ & 5.9495 & 0.2585 \\
\hline $\mathrm{TDS}^{2}$ & 2.7376 & 0.2585 & TDS $^{1}$ & 5.3752 & 0.2585 \\
\hline $\mathrm{TDS}^{3}$ & 2.9723 & 0.4863 & TDS $^{4}$ & 6.6641 & 0.4863 \\
\hline $\mathrm{TDS}^{4}$ & 4.1477 & 0.4863 & $\mathrm{TDS}^{3}$ & 4.5897 & 0.4863 \\
\hline $\mathrm{TDS}^{5}$ & 1.9545 & 0.7138 & $\operatorname{TDS}^{6}$ & 6.2345 & 0.7138 \\
\hline $\operatorname{TDS}^{6}$ & 2.7678 & 0.7138 & $\mathrm{TDS}^{5}$ & 4.2573 & 0.7138 \\
\hline $\operatorname{TDS}^{7}$ & 3.8423 & 1.746 & $\operatorname{TDS}^{8}$ & 6.3694 & 1.746 \\
\hline $\mathrm{TDS}^{8}$ & 5.618 & 1.746 & $\mathrm{TDS}^{7}$ & 4.1783 & 1.746 \\
\hline $\mathrm{TDS}^{9}$ & 4.6538 & 1.0424 & $\mathrm{TDS}^{10}$ & 3.87 & 1.0424 \\
\hline $\mathrm{TDS}^{10}$ & 3.5261 & 1.0424 & $\mathrm{TDS}^{9}$ & 5.2696 & 1.0424 \\
\hline $\mathrm{TDS}^{11}$ & 2.584 & 0.7729 & $\mathrm{TDS}^{12}$ & 6.1144 & 0.7729 \\
\hline $\mathrm{TDS}^{12}$ & 3.8006 & 0.7729 & $\mathrm{TDS}^{11}$ & 3.9005 & 0.7729 \\
\hline $\mathrm{TDS}^{13}$ & 2.4143 & 0.5879 & $\mathrm{TDS}^{14}$ & 2.9011 & 0.5879 \\
\hline $\mathrm{TDS}^{14}$ & 5.3541 & 0.5879 & $\mathrm{TDS}^{13}$ & 4.335 & 0.5879 \\
\hline
\end{tabular}

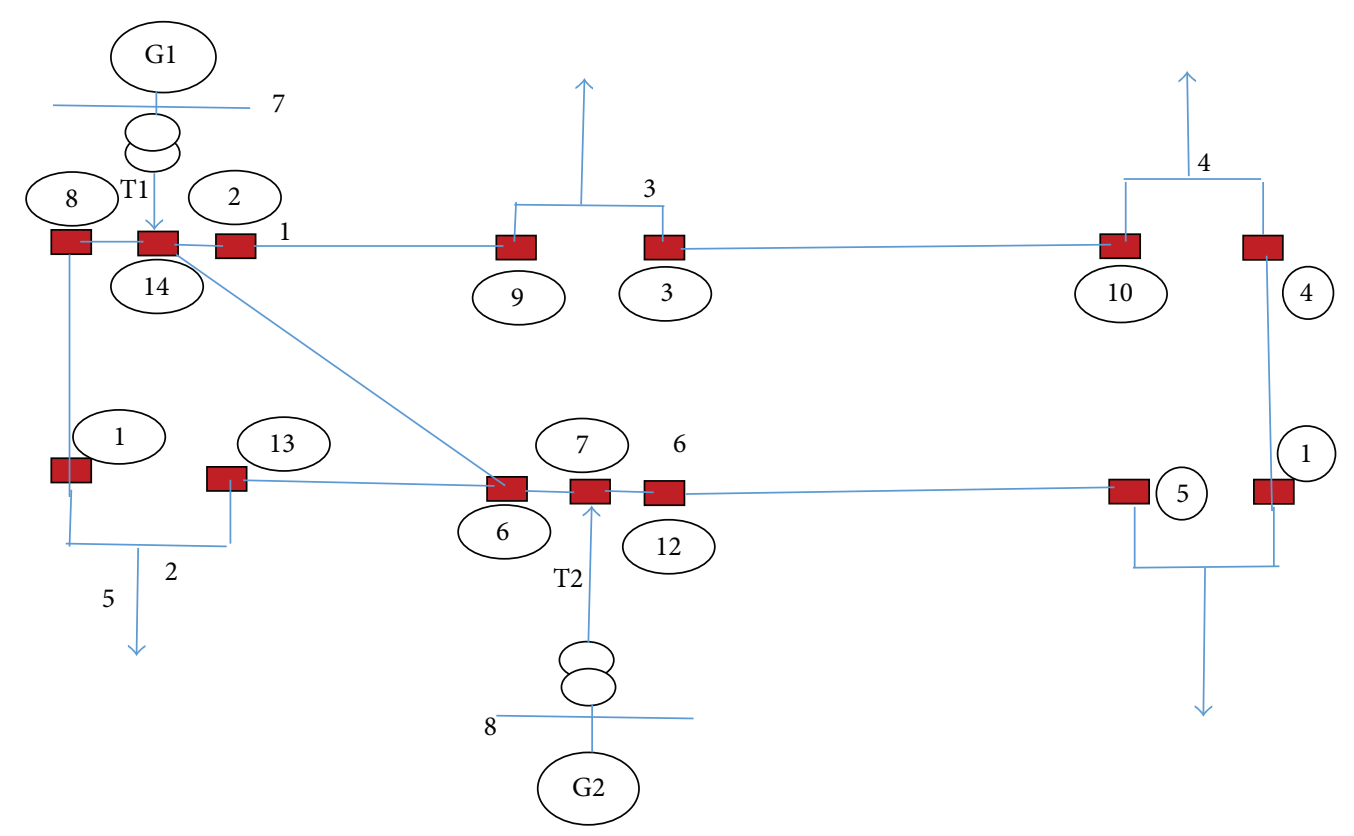

FIGURE 11: Model for the IEEE 8-bus system [3]. 
TABLE 12: Values of constants $e^{i}, f^{i}, g^{i}$, and $h^{i}$ for Model III.

\begin{tabular}{|c|c|c|c|c|c|}
\hline \multirow{2}{*}{$\begin{array}{l}T_{\text {backup }}^{i} \\
\mathrm{p}\end{array}$} & \multicolumn{5}{|c|}{$T_{\text {primary }}^{i}$} \\
\hline & $e^{i}$ & $f^{i}$ & $\mathrm{q}$ & $g^{i}$ & $h^{i}$ \\
\hline 8 & 4.0909 & 1.746 & 1 & 5.3752 & 0.2585 \\
\hline 11 & 1.2886 & 0.7729 & 1 & 5.3752 & 0.2585 \\
\hline 8 & 2.9323 & 1.746 & 1 & 2.5311 & 0.2585 \\
\hline 3 & 0.6213 & 0.4863 & 2 & 2.7376 & 0.2585 \\
\hline 3 & 1.6658 & 0.4863 & 2 & 5.9495 & 0.2585 \\
\hline 10 & 0.0923 & 1.0424 & 3 & 4.5897 & 0.4863 \\
\hline 10 & 2.561 & 1.0424 & 3 & 2.9723 & 0.4863 \\
\hline 13 & 1.4995 & 0.5879 & 3 & 4.5897 & 0.4863 \\
\hline 1 & 0.8869 & 0.2585 & 4 & 4.1477 & 0.4863 \\
\hline 1 & 1.5243 & 0.2585 & 4 & 6.6641 & 0.4863 \\
\hline 12 & 2.5444 & 0.7729 & 5 & 4.2573 & 0.7138 \\
\hline 12 & 1.4549 & 0.7729 & 5 & 1.9545 & 0.7138 \\
\hline 14 & 1.7142 & 0.5879 & 5 & 4.2573 & 0.7138 \\
\hline 3 & 1.4658 & 0.4863 & 6 & 6.2345 & 0.7138 \\
\hline 3 & 1.1231 & 0.2585 & 6 & 6.2345 & 0.7138 \\
\hline 11 & 2.1436 & 0.7729 & 7 & 4.1783 & 1.746 \\
\hline 2 & 2.0355 & 0.2585 & 7 & 4.1783 & 1.746 \\
\hline 11 & 1.9712 & 0.7729 & 7 & 3.8423 & 1.746 \\
\hline 2 & 1.8718 & 0.2585 & 7 & 3.8423 & 1.746 \\
\hline 13 & 1.8321 & 0.5879 & 9 & 5.2696 & 1.0424 \\
\hline 4 & 3.4386 & 0.4863 & 9 & 5.2696 & 1.0424 \\
\hline 13 & 1.618 & 0.5879 & 9 & 4.6538 & 1.0424 \\
\hline 4 & 3.0368 & 0.4863 & 9 & 4.6538 & 1.0424 \\
\hline 14 & 2.0871 & 0.5879 & 11 & 3.9005 & 0.7729 \\
\hline 6 & 1.8138 & 0.7138 & 11 & 3.9005 & 0.7729 \\
\hline 14 & 1.4744 & 0.5879 & 11 & 2.584 & 0.7729 \\
\hline 6 & 1.1099 & 0.7138 & 11 & 2.584 & 0.7729 \\
\hline 8 & 3.3286 & 1.746 & 12 & 3.8006 & 0.7729 \\
\hline 2 & 0.4734 & 0.2585 & 12 & 3.8006 & 0.7729 \\
\hline 8 & 4.5736 & 1.746 & 12 & 6.1144 & 0.7729 \\
\hline 2 & 1.5432 & 0.2585 & 12 & 6.1144 & 0.7729 \\
\hline 12 & 2.7269 & 0.7729 & 13 & 4.335 & 0.5879 \\
\hline 6 & 1.6085 & 0.7138 & 13 & 4.335 & 0.5879 \\
\hline 12 & 1.836 & 0.7729 & 13 & 2.4143 & 0.5879 \\
\hline 10 & 2.026 & 1.0424 & 14 & 2.9011 & 0.5879 \\
\hline 4 & 0.8757 & 0.4863 & 14 & 2.9011 & 0.5879 \\
\hline 10 & 2.7784 & 1.0424 & 14 & 5.3541 & 0.5879 \\
\hline 4 & 2.5823 & 0.4863 & 14 & 5.3541 & 0.5879 \\
\hline
\end{tabular}

\section{Nomenclature}

AI: Artificial intelligence

CT: $\quad$ Current transformer

DOCR: Directional overcurrent relay

FA: Firefly algorithm

GA: Genetic algorithm

NIA: Nature-inspired algorithm
PS: Plug setting

PSO: Particle swarm optimization

TDS: Time dial setting.

\section{Conflicts of Interest}

The authors declare that there are no conflicts of interest regarding this publication. 
TABLE 13: Primary/backup relays and fault currents for the 8-bus test system.

\begin{tabular}{lccc}
\hline Primary relay & $I_{f}(\mathrm{~A})$ (primary) & Backup relay & $I_{f}(\mathrm{~A})$ (backup) \\
\hline 1 & 2666.3 & 6 & 2666.3 \\
2 & 5374.8 & 1 & 804.7 \\
2 & 5374.8 & 7 & 1531.5 \\
3 & 3325.6 & 2 & 3325.6 \\
4 & 2217.1 & 3 & 2217.1 \\
5 & 1334.3 & 4 & 1334.3 \\
6 & 4975 & 5 & 403.6 \\
6 & 4975 & 14 & 1533 \\
7 & 4247.6 & 5 & 403.6 \\
7 & 4247.6 & 13 & 805.5 \\
8 & 4973.2 & 7 & 1531.5 \\
8 & 4973.2 & 9 & 403.2 \\
9 & 1420.9 & 10 & 1420.9 \\
10 & 2313.5 & 11 & 2313.5 \\
11 & 3474.3 & 12 & 3474.3 \\
12 & 5377 & 13 & 805.5 \\
12 & 5377 & 14 & 1533 \\
13 & 2475.7 & 8 & 2475.7 \\
14 & 4246.4 & 1 & 804.7 \\
\hline
\end{tabular}

TABLE 14: The main characteristics of the 8-bus test system.

\begin{tabular}{lccc}
\hline & & & $I_{P}(\mathrm{~A})$ \\
Relay & CT ratio & Min & Max \\
\hline 1 & $1200 / 5$ & 120 & 480 \\
2 & $1200 / 5$ & 120 & 480 \\
3 & $800 / 5$ & 80 & 320 \\
4 & $1200 / 5$ & 120 & 480 \\
5 & $1200 / 5$ & 120 & 480 \\
6 & $1200 / 5$ & 120 & 480 \\
7 & $800 / 5$ & 80 & 320 \\
8 & $1200 / 5$ & 120 & 480 \\
9 & $800 / 5$ & 80 & 320 \\
10 & $1200 / 5$ & 120 & 480 \\
11 & $1200 / 5$ & 120 & 480 \\
12 & $1200 / 5$ & 120 & 480 \\
13 & $1200 / 5$ & 120 & 480 \\
\hline
\end{tabular}

\section{References}

[1] A. J. Urdaneta, R. Nadira, and L. G. Pérez Jiménez, “Optimal Coordination of Directional Overcurrent Relays in Interconnected Power Systems," IEEE Transactions on Power Delivery, vol. 3, no. 3, pp. 903-911, 1988.

[2] D. Birla, R. P. Maheshwari, H. O. Gupta, K. Deep, and M. Thakur, "Application of random search technique in directional overcurrent relay coordination," International Journal of Emerging Electric Power Systems, vol. 7, no. 1, pp. 1-16, 2006.

[3] H. R. E. H. Bouchekara, M. Zellagui, and M. A. Abido, "Optimal coordination of directional overcurrent relays using a modified electromagnetic field optimization algorithm," Applied Soft Computing, vol. 54, pp. 267-283, 2017.

[4] K. Deep, Engineering Optimization: An Introduction with Metaheuristic Applications, 2007.

[5] M. Sulaiman, A. Ashfaq, K. Asfandyar, and S. Muhammad, "Hybridized symbiotic organism search algorithm for the optimal operation of directional over-current relays," Complexity, 2017.

[6] H. B. Elrafie and M. R. Irving, "Linear programming for directional overcurrent relay coordination in interconnected power systems with constraint relaxation," Electric Power Systems Research, vol. 27, no. 3, pp. 209-216, 1993. 
[7] A. S. Braga and J. T. Saraiva, "Coordination of overcurrent directional relays in meshed networks using the simplex method," in Proceedings of the 1996 8th Mediterranean Electrotechnical Conference, MELECON'06. Part 3 (of 3), pp. 1535-1538, May 1996.

[8] H. Askarian Abyaneh and R. Keyhani, "Optimal co-ordination of overcurrent relays in power system by dual simplex method," in Proceedings of the AUPEC Conference, vol. 3, pp. 440-445, 1995.

[9] A. Y. Abdelaziz, H. E. A. Talaat, A. I. Nosseir, and A. A. Hajjar, "An adaptive protection scheme for optimal coordination of overcurrent relays," Electric Power Systems Research, vol. 61, no. 1, pp. 1-9, 2002.

[10] N. A. Laway and H. O. Gupta, "A method for adaptive coordination of overcurrent relays in an interconnected power system," in Proceedings of the Developments in Power System Protection, pp. 240-243, 1993.

[11] X.-S. Yang, "Firefly algorithms for multimodal optimization," in Proceedings of the International symposium on stochastic algorithms, vol. 5792, pp. 169-178, Springer.

[12] M. Sulaiman, A. Salhi, B. I. Selamoglu, and O. B. Kirikchi, "A plant propagation algorithm for constrained engineering optimisation problems," Mathematical Problems in Engineering, vol. 2014, Article ID 627416, 10 pages, 2014.

[13] M. Sulaiman and A. Salhi, "A seed-based plant propagation algorithm: The feeding station model," The Scientific World Journal, vol. 2015, Article ID 904364, 2015.

[14] M. M. Mansour, S. F. Mekhamer, and N. E.-S. El-Kharbawe, "A modified particle swarm optimizer for the coordination of directional overcurrent relays," IEEE Transactions on Power Delivery, vol. 22, no. 3, pp. 1400-1410, 2007.

[15] H. H. Zeineldin, E. F. El-Saadany, and M. M. A. Salama, "Optimal coordination of overcurrent relays using a modified particle swarm optimization," Electric Power Systems Research, vol. 76, no. 11, pp. 988-995, 2006.

[16] F. Razavi, H. A. Abyaneh, M. Al-Dabbagh, R. Mohammadi, and H. Torkaman, "A new comprehensive genetic algorithm method for optimal overcurrent relays coordination," Electric Power Systems Research, vol. 78, no. 4, pp. 713-720, 2008.

[17] K. A. Brown and N. Tyle, "Expert system for overcurrent protective device coordination," in Proceedings of the Rural Electric Power Conference, Papers Presented at the 30th Annual Conference., 1986.

[18] S. J. Lee, S. H. Yoon, M.-C. Yoon, and J.-K. Jang, "An expert system for protective relay setting of transmission systems," in Proceedings of the Conference Papers Power Industry Computer Application Conference, pp. 296-302, Seattle, Wash, USA.

[19] G. Decher and J. Hong, "Buildup of ultrathin multilayer films by a self-assembly process, 1 consecutive adsorption of anionic and cationic bipolar amphiphiles on charged surfaces," Makromolekulare Chemie: Macromolecular Symposia, vol. 46, no. 1, pp. 321-327, 1991.

[20] J. Wang and J. Trecat, "RSVIES - A relay setting value identification expert system," Electric Power Systems Research, vol. 37, no. 2, pp. 153-158, 1996.

[21] H. A. Abyane, K. Faez, and H. K. Karegar, "New method for overcurrent relay $(\mathrm{O} / \mathrm{C})$ using neural network and fuzzy logic," in Proceedings of the 1997 IEEE TENCON Conference, vol. 1, pp. 407-410, December 1997. 


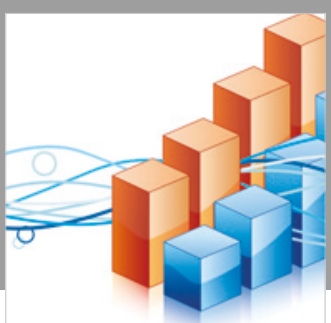

Advances in

Operations Research

\section{-n-m}
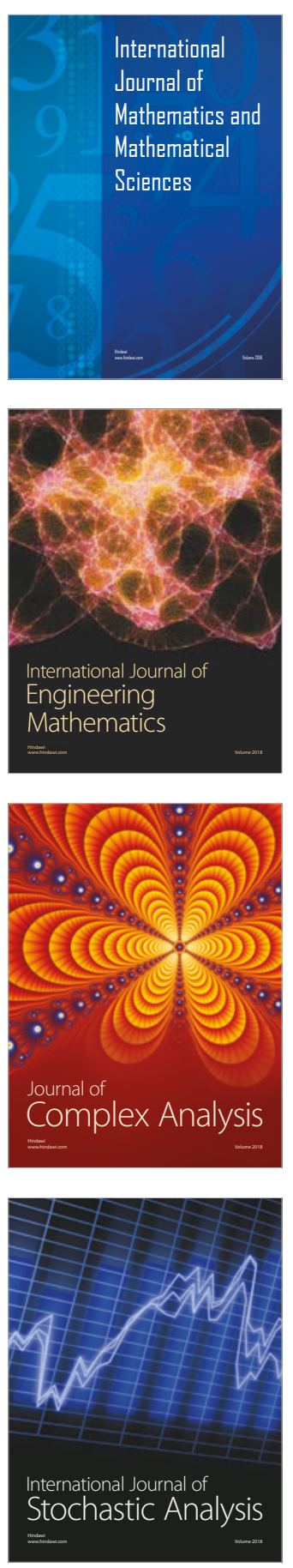
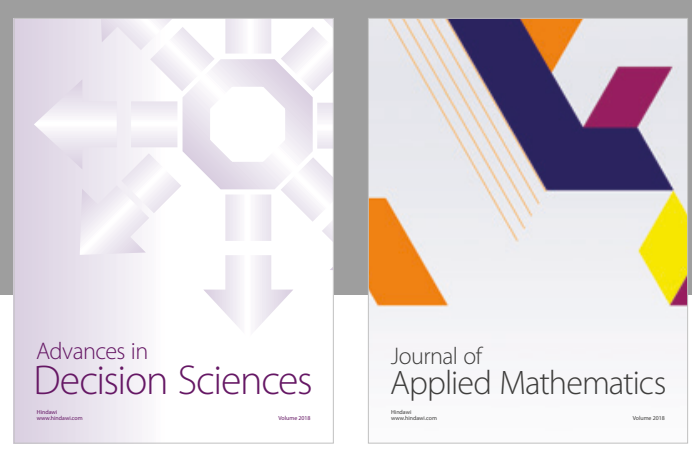

Journal of

Applied Mathematics
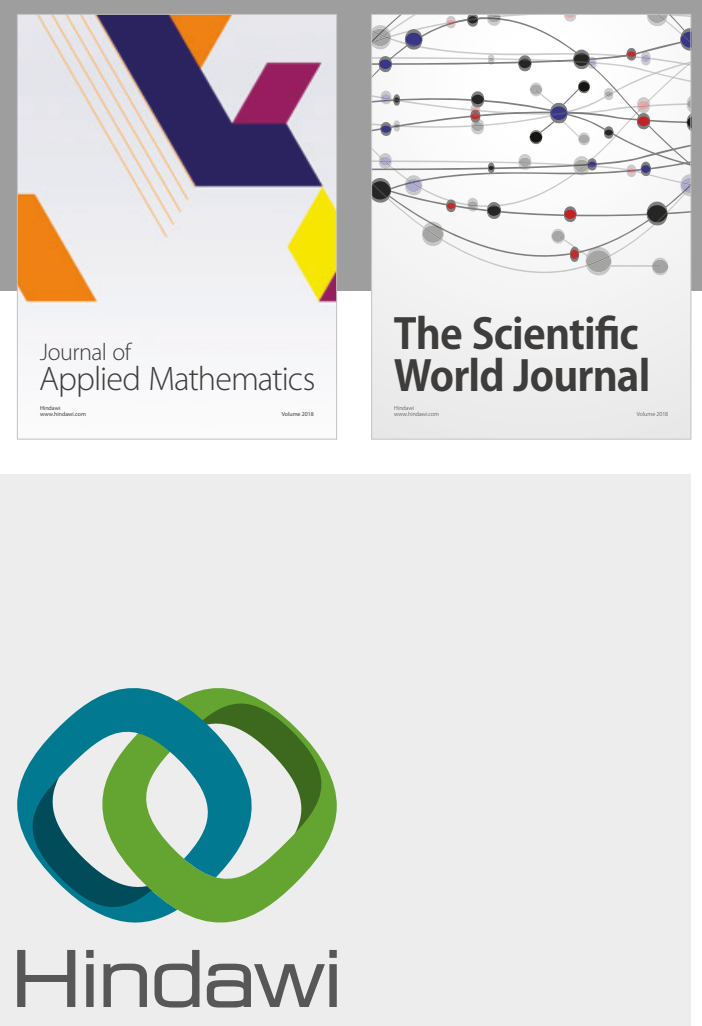

Submit your manuscripts at

www.hindawi.com

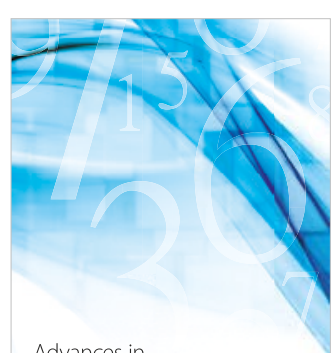

Advances in
Numerical Analysis
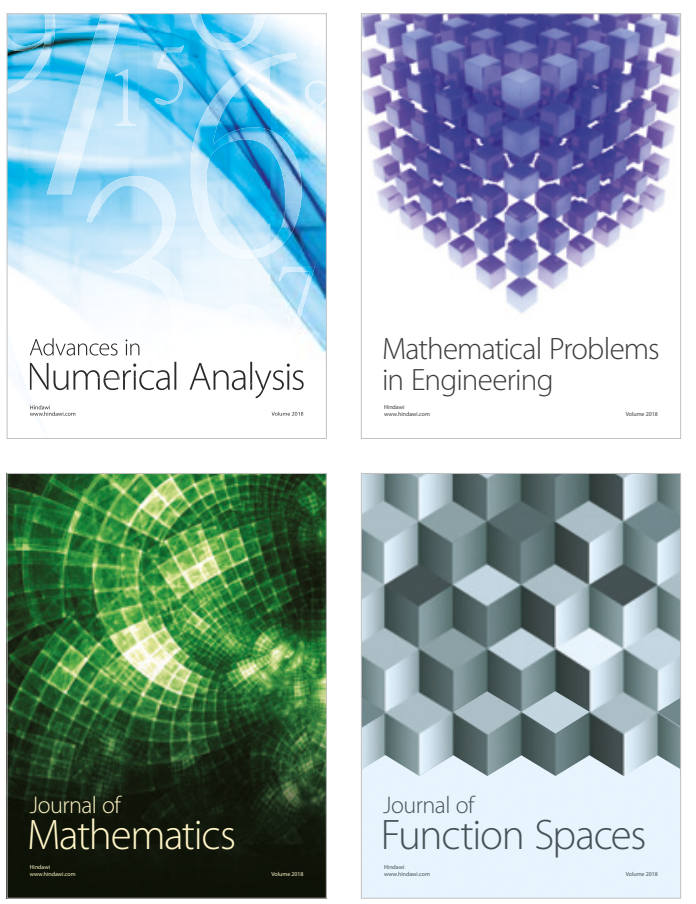

Mathematical Problems in Engineering

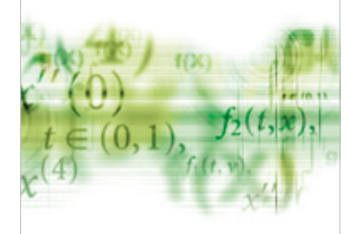

International Journal of

Differential Equations

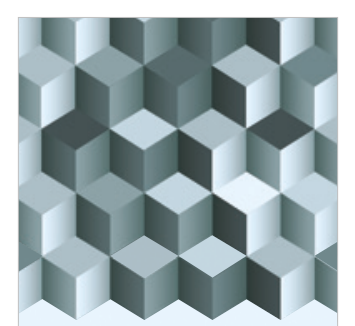

Journal of

Function Spaces
The Scientific

World Journal

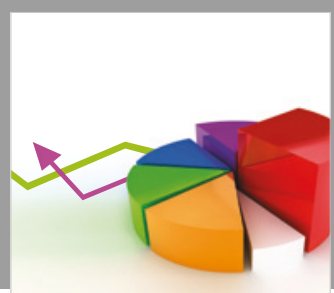

Journal of

Probability and Statistics
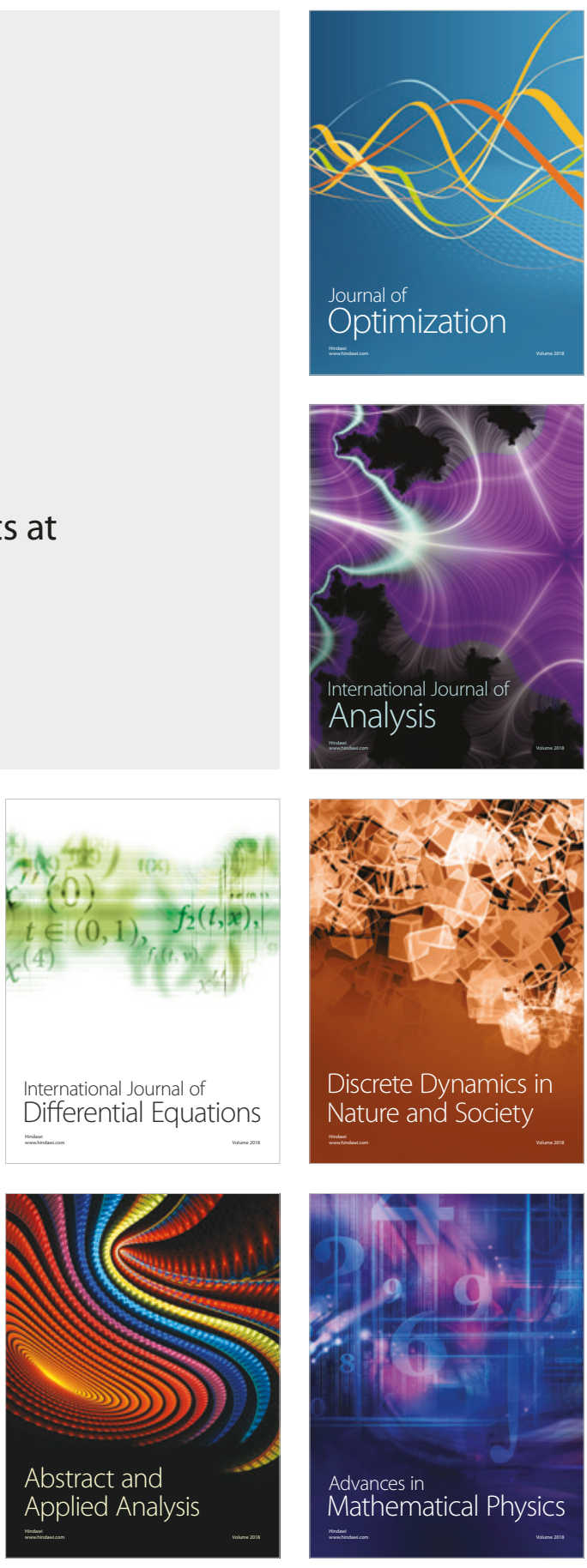